Article

\title{
The Prospects for Processing Reservoir Oil Sludge into Hydrocarbons by Low-Temperature Hydrogenation in Sorbing Electrochemical Matrices in Comparison with Conventional High-Temperature Hydrocracking
}

\author{
Anton Maximov ${ }^{1}$, Aslan Tsivadze ${ }^{2}$, Alexander Fridman ${ }^{2}$, Tatyana Kuchinskaya ${ }^{1, *}$, \\ Alexander Novikov ${ }^{2}$, Maxim Shabanov ${ }^{2}$ and Evgeny Naranov ${ }^{1}$ (D) \\ 1 1Federal State Budgetary Institution of Science A.V. Topchiev Institute of Petrochemical Synthesis, \\ Russian Academy of Sciences, Moscow 119991, Russia; max@ips.ac.ru (A.M.); naranov@ips.ac.ru (E.N.) \\ 2 2Federal State Budgetary Institution of Science A.N. Frumkin Institute of Physical Chemistry \\ and Electrochemistry, Russian Academy of Sciences, Moscow 119071, Russia; tsiv@phyche.ac.ru (A.T.); \\ fridman42@mail.ru (A.F.); novikov.a.k.42@gmail.com (A.N.); sha444@yandex.ru (M.S.) \\ * Correspondence: kuchinskaya@ips.ac.ru
}

Received: 24 August 2020; Accepted: 10 October 2020; Published: 14 October 2020

check for updates

\begin{abstract}
In this paper, we developed an effective method for purifying oil sludge using a sorbing electrochemical matrix and assessed the prospects of this method in comparison with conventional hydrocracking. We synthesized Ni-W supported hydrocracking catalysts with different morphology and studied their activity under various conditions, we compared the obtained catalysts with commercial catalyst SGK-5. We demonstrated that the introduction of a secondary mesoporous structure in the catalyst leads to an increase in the yield of light fractions to $52 \mathrm{wt} . \%$. The possibility is demonstrated to obtain hydrocarbons from reservoir oil sludge, dispersed into an aqueous solution of detergent, by the method of low-temperature hydrogenation in sorbing electrochemical matrices. The obtained product was characterized by low viscosity, low content of transition metals ( $<320$ ppm), and sulphur (<260 ppm).
\end{abstract}

Keywords: oil sludge; detergent; water-oil emulsions; low-temperature hydrogenation; hydrokracking

\section{Introduction}

The process of oil production, transportation, and storage inevitably leads to the formation of a large amount of oil industry wastes-hard and liquid oil sludges. Oil sludges are complex mixtures containing water, oil products and mineral impurities (clays, metal oxides, sand, etc.), which cause an environmental hazard [1]. Since oil sludges contain polyaromatic compounds (polyaromatic hydrocarbons) that exhibit carcinogenic and mutagenic properties, oil sludges are also of serious hazard for a human being [2]. Therefore, the problem of proper disposal or further processing of oil sludges accumulated at oil production facilities and oil refineries is particularly acute. There are several ways of oil sludge disposal, however, primarily, this problem is solved by incinerating accumulated wastes in special furnaces. The common solutions are processing through integrated thermal treatment (joint pyrolysis) of reservoir oil sludges [3-5] and hydrocracking [6].

Oil sludge contains valuable hydrocarbons that may be involved in processing in order to obtain light fractions and used as components of commercial products. Today one of the most efficient refining processes is hydrocracking. The process is carried out at high hydrogen pressure (up to $25 \mathrm{MPa}$ ) and temperature (up to $450{ }^{\circ} \mathrm{C}$ ), as well as at a high ratio of $\mathrm{H}_{2}$-to-feed stock, which makes it possible to 
obtain a high yield of a wide range of high-quality components of basic petroleum products-liquefied gases, jet fuels and diesel fuels, oil components, etc. The main advantage of hydrocracking is the ability to process both distillate and heavy residual fractions.

For the efficient hydrocracking of oil sludge, it is necessary that the porous catalyst system allows the bulk molecules of the oil sludge contacting the active sites. When using widespread sulfide hydrocracking catalysts containing zeolites as an acidic carrier, diffusion restrictions arise due to the steric factor, at which the size of the oil sludge molecules may exceed zeolite pore size preventing hydrocarbon molecules access to the active sites of the catalyst. Therefore, an actual task is the synthesis of effective supports as a result of the synergy of the properties of zeolites and mesoporous materials for hydrocracking of heavy oil residues.

Another promising and more environmentally compatible method is the processing of reservoir oil sludge by its dispersion into solutions of detergents based on surface-active substances (SAS) and complexing agents followed by separation from water-oil emulsions of oil with a high content of sulphur and metals as well as sulphur-containing surface-active substances [4,7]. Oil sludge forms stable emulsions with water [8], therefore, active research is being carried out to find and synthesize new detergents capable to dissolve oil sludge [9]. Much attention is paid to emulsions of known ionic SAS and complexing reagents. Biphilic molecules are incorporated into resins and asphaltenes containing metal complexes. Suspended particles are extracted, sorbed on ion-exchange resins or separated using membranes, and fuel oil is isolated from water-oil emulsions [10].

Previously, our research team has developed a detergent (hereinafter-polycomplexone) that is a mixture of sodium salts of iminodiacetate derivatives of tri- and diglycerides of fatty acids and polymucosaccharides [11], used for dispersing oil sludges and destructing sulphur-containing compounds and metal complexes in water-oil emulsions [12]. Low-sulphur, low-viscosity, medium-density oil with a low content of metals was extracted from them.

For a deeper purification of oil sludge at the stage of obtaining water-oil emulsions, we proposed a method of low-temperature hydrogenation in sorbing electrochemical matrices. Yet, it is worth noting that the details of using this method have not been studied enough. Currently, known are $\mathrm{H}^{+}$- and $\mathrm{OH}^{-}$-conductive polymeric membranes and fabrics [13-16] and electrically-conductive sorbents [17]. They are used in fuel cells, analytical instrumentation, sensors, and chemical energy sources, as well as in electroplating and water treatment processes. There have been recorded electrochemical matrices based on sorption-active cathode-polarized anion-conductive electrical conductors for hydrogen production. Used as conductors were fabrics the fibers of which were chemically encapsulated in a layer of active carbon with grafted ethanolamine polyvinylchloride (PVC) derivatives and $\mathrm{NaOH}$ aquacomplexes $[18,19]$.

In this paper, we have assessed the prospects of processing reservoir oil sludges into hydrocarbons by the method of low-temperature hydrogenation in sorbing electrochemical matrices.

To compare the efficiency of the proposed method, we synthesized a series of catalysts for oil sludge hydrocracking containing micro/mesoporous materials, and we analyzed obtained data with the commercial catalyst SGK-5.

\section{Materials and Methods}

\subsection{Materials and Equipment}

In the present work oil sludge was used with density $\rho=0.998 \mathrm{~g} / \mathrm{cm}^{3}$, refraction index $\eta=7.08 \mathrm{mPa}$, an $\mathrm{H}_{2} \mathrm{O}$ content of $29 \%$, and a weight content of the following impurities:

$\mathrm{S}-4.67 \%, \mathrm{~W}-0.029 \%, \mathrm{Ni}-0.0079 \%, \mathrm{Zn}-0.094 \%, \mathrm{Cu}-0.0022 \%, \mathrm{Fe}-0.102 \%$ (calculated with reference to dried substance). Detergent produced by Tsentr LLC, Russia: the content of iminodiacetate derivatives of mucosaccharides is $31 \%$, iminodiacetate derivatives of triglycerides of fatty acids- $34 \%$, $\mathrm{H}_{2} \mathrm{O}-35 \%$. We also used nitrilotriacetic acid (reachem.) and $\mathrm{NaOH}$ (reachem). 
When preparing micro/mesoporous aluminosilicates, tetraethoxysilane $(\mathrm{EtO})_{4} \mathrm{Si}$ (produced by Aldrich company, St. Louis, MO, USA) and silicon oxide in the form of fumed silica (produced by Aldrich company, St. Louis, MO, USA) with a basic substance content of at least $98 \%$ were used as silicon sources. Aluminum isopropoxide (iso-PrO) ${ }_{3} \mathrm{Al}$ (produced by Aldrich company, St. Louis, MO, USA), secondary aluminum butoxide (sec-BuO) ${ }_{3} \mathrm{Al}$ (produced by Merck company, Kenilworth, NJ, USA), and sodium aluminate $\mathrm{NaAlO}_{2}$ (produced by Aldrich company, St. Louis, MO, USA) were used as aluminum sources.

Triblock copolymer of polyethylene and polypropylene oxide Pluronic $\mathrm{P} 123,\left(\mathrm{EO}_{20} \mathrm{PO}_{70} \mathrm{EO}_{20}\right)$, with molecular weight of 5800 (produced by Aldrich company, St. Louis, MO, USA), tetraethylammonium hydroxide TEAOH ( $35 \%$ solution in water), tetrapropylammonium hydroxide TPAOH $(20 \%$ solution in water), cetyltrimethylammonium bromide $\mathrm{CTAB} \mathrm{C}_{19} \mathrm{H}_{24} \mathrm{BrN}$ (produced by Aldrich company, St. Louis, MO, USA), and triethanolamine (produced by Aldrich company, St. Louis, MO, USA) were used as structuring agents.

When the metals were deposited on the support, ammonium metatungstate $\left(\mathrm{NH}_{4}\right)_{6} \mathrm{H}_{2} \mathrm{~W}_{12} \mathrm{O}_{40} \cdot \mathrm{H}_{2} \mathrm{O}$ and high purity nickel nitrate $\mathrm{Ni}\left(\mathrm{NO}_{3}\right)_{2} \cdot 6 \mathrm{H}_{2} \mathrm{O}$ were used as the sources of $\mathrm{Ni}$ and W. "Reference" n-heptane; ultra-high purity toluene; high purity oxalic acid; high purity glycerin; high purity elementary sulfur.

The content of metals in oil sludge was determined by the method of energy-dispersive $x$-ray fluorescent spectrometry on an ARL Perform' $X$ analyzer (Thermo Fisher Scientific, Waltham, MA, USA; New Wave). The content of iminodiacetate derivatives of polymucosaccharides was determined by potentiometric titration. The group composition of oil was analyzed by determining the hydrocarbon composition of liquid oil products using fluorescent indicator adsorption.

\subsection{Synthesis of Catalysts and Methodology Catalytic Process}

We have synthesized aluminosilicate zeolites with an ordered mesoporous structure (Scheme 1).

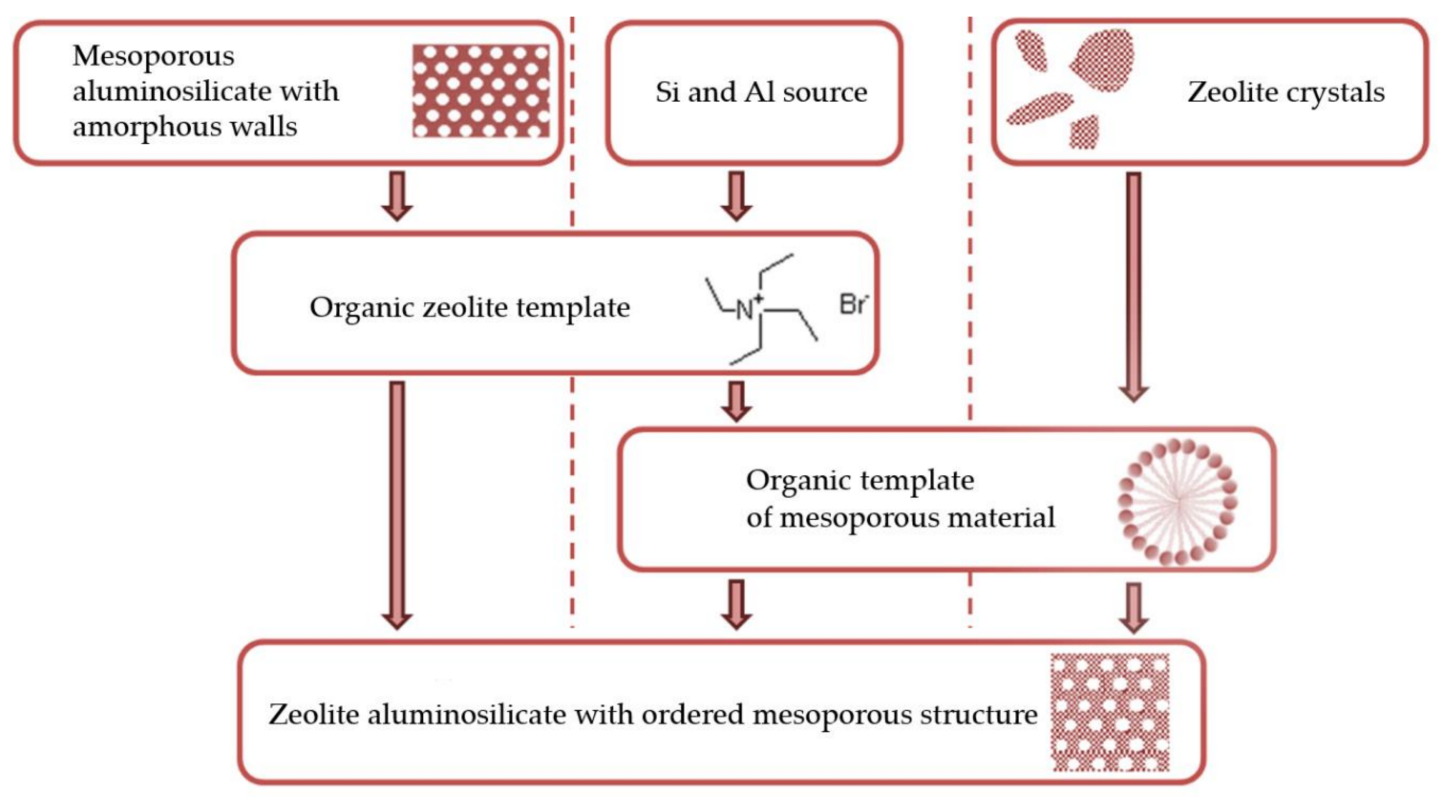

Scheme 1. Synthesis scheme for zeolite aluminosilicate with an ordered mesoporous structure.

The first type of support, a structured micro/mesoporous aluminosilicate of the SBA-15/ZSM-5 type, was obtained by bitemplate synthesis. Tetraethoxysilane $(\mathrm{EtO})_{4} \mathrm{Si}$ and aluminum isopropoxide (iso-PrO) $)_{3} \mathrm{Al}$ were used as a source of silicon and aluminum respectively; a triblock copolymer of polyethylene and polypropylene oxide Pluronic $\mathrm{P} 123,\left(\mathrm{EO}_{20} \mathrm{PO}_{70} \mathrm{EO}_{20}\right)$ with molecular weight of 5800 was used as a mesostructuring agent, and tetrapropylammonium hydroxide TPAOH $(20 \%$ solution in water) was used as a microstructuring agent. 
In the preparation of structured micro/mesoporous aluminosilicates of the SBA-15/zeolite BEA type, the method of zeolites crystallization in the prepared mesoporous material was used; tetraethoxysilane $(\mathrm{EtO})_{4} \mathrm{Si}$ and silicon, which is a part of the mesoporous material SBA 15, were used as silicon sources, secondary aluminum butoxide $(\mathrm{sec}-\mathrm{BuO})_{3} \mathrm{Al}$ was used as aluminum source, tetraethylammonium hydroxide $\mathrm{TEAOH} \mathrm{(35 \%} \mathrm{solution} \mathrm{in} \mathrm{water)} \mathrm{was} \mathrm{used} \mathrm{as} \mathrm{a} \mathrm{microstructuring} \mathrm{agent.}$

A structured micro/mesoporous aluminosilicate of the TUD/zeolite BEA type was obtained by the method of zeolite mesostructuring. The source of silicon was tetraethoxysilane $(\mathrm{EtO})_{4} \mathrm{Si}$ and silicon which is a part of commercial zeolite BEA, the source of aluminum was only aluminum which is a part of commercial zeolite BEA, and triethanolamine was used as mesostructuring agent.

The synthesis of a structured micro/mesoporous support of the SBA-15/MFI type was carried out by preparing a mesoporous material SBA-15 and further crystallization of zeolite in its walls. Tetraethoxysilane $(\mathrm{EtO})_{4} \mathrm{Si}$ and silicon, which is part of the mesoporous material SBA 15 , were used as silicon sources; sodium aluminate $\mathrm{NaAlO}_{2}$ was used as aluminum source, and tetrapropylammonium hydroxide TPAOH ( $20 \%$ solution in water) was used as a microstructuring agent.

And the last type of support, micro/mesoporous material MCM-41/ZSM-5, was obtained by bitemplate synthesis, where $\mathrm{SiO}_{2}$ in the form of fumed silica and tetraethoxysilane $(\mathrm{EtO})_{4} \mathrm{Si}$ were used as silicon sources; and sodium aluminate $\mathrm{NaAlO}_{2}$ was used as an aluminum source. Cetyltrimethylammonium bromide $\mathrm{CTAB} \mathrm{C}_{19} \mathrm{H}_{24} \mathrm{BrN}$ was used as a mesostructuring agent, and tetrapropylammonium hydroxide TPAOH ( $20 \%$ solution in water) was used as a mi-crostructuring agent [20].

ZSM-5/SBA-15 materials were obtained in two ways: by double templating synthesis (ZSM-5/SBA-15 (1)) according to the method described in [21] and by the method of forming zeolite in the walls of amorphous SBA-15 (ZSM-5/SBA-15 (2)) [22]. The synthesis of BEA/SBA-15 material by the formation of zeolite in the mesoporous SBA-15 was carried out according to the method proposed in [23]. BEA/TUD material was obtained by mesostructuring of zeolite-BEA [24].

The deposition of metals on the support was carried out as described in [25]. Mass con-tents of metals (in terms of oxides) used in the preparation of Ni-W catalysts for all synthesized materials were 32.7 mass. $\%$ for $\mathrm{WO}_{3}$ and $20.0 \%$ for $\mathrm{NiO}$, respectively. The deposition of metals was carried by wet impregnation out in one stage. Ammonium metatungstate $\left(\mathrm{NH}_{4}\right)_{6} \mathrm{H}_{2} \mathrm{~W}_{12} \mathrm{O}_{40} \cdot \mathrm{H}_{2} \mathrm{O}$ and nickel nitrate $\mathrm{Ni}\left(\mathrm{NO}_{3}\right)_{2} \cdot 6 \mathrm{H}_{2} \mathrm{O}$ were used as the sources of metals. A sample in an amount of $1.0 \mathrm{~g}$ was placed in a weighing bottle and, while stirring with a spatula, $0.74 \mathrm{~g}$ of ammonium metatungstate and $1.64 \mathrm{~g}$ of nickel nitrate in a $0.5 \mathrm{M}$ solution of oxalic acid were added to it. The mixture was thoroughly mixed for $30 \mathrm{~min}$, the weighting bottle was covered with a lid and left overnight. An open weighting bottle with a sample was placed in a drying box and dried with air circulation for $3 \mathrm{~h}$ at $90^{\circ} \mathrm{C}$, while periodically stirring the mixture with a spatula. Then it was dried at a temperature of $120^{\circ} \mathrm{C}$ for $3 \mathrm{~h}$. The sample was transferred into a porcelain cup and calcined in a muffle furnace at $550{ }^{\circ} \mathrm{C}$ for $4 \mathrm{~h}$.

The reaction of converting metal oxides into the sulfide form was carried out in a $50 \mathrm{~mL}$ autoclave equipped with a magnetic stirrer. A solution of sulfur in toluene was used as a sulfiding agent. $1 \mathrm{~g}$ of $\mathrm{NiO}-\mathrm{WO}_{3}$ /support sample was placed in an autoclave, $0.7 \mathrm{~g}$ of elemental sulfur and $5 \mathrm{~mL}$ of toluene were added thereto. The sulfur was preliminarily ground in a mortar to a finely dispersed state. The autoclave was filled with hydrogen to a pressure of $50 \mathrm{~atm}$., placed in an oven and heated to $350{ }^{\circ} \mathrm{C}$ with intense stirring for $5 \mathrm{~h}$. After completion of the reaction, the autoclave was cooled to room temperature and the pressure was released. The obtained $\mathrm{NiS}-\mathrm{WS}_{2} /$ support sample was washed three times with hot toluene, then dried in argon flow.

Conditions for testing catalyst samples in autoclave, including the substrate: metal ratio, were selected on the basis of the analysis of literature references and also on the calculation that the presence of residual sulphur in the feedstock would not fundamentally affect the properties of catalysts. The experiments were conducted at 350 to $400{ }^{\circ} \mathrm{C}$ and an initial hydrogen pressure of $50 \mathrm{~atm}$. The ratio $\mathrm{H}_{2} /$ feedstock was $1400 \mathrm{ncm}^{3} / \mathrm{cm}^{3}$. 
Catalytic experiments on hydrocracking of oil sludge were carried out at elevated pressure and temperature, and thorough mixing of the reaction mixture. The reactions were carried out in a steel autoclave (with internal volume of $50 \mathrm{~cm}^{3}$ ) equipped with a magnetic stirrer and a manometer in hydrogen atmosphere.

The autoclave was charged with $200 \mathrm{mg}$ or $500 \mathrm{mg}$ of finely ground catalyst and $3 \mathrm{~mL}$ of raw material. The ratio $\mathrm{H}_{2}{ }^{-} /$to feedstock was in the range from 800 to $1700 \mathrm{ncm}^{3} / \mathrm{cm}^{3}$. The reaction was carried out at the temperature range from 300 to $500^{\circ} \mathrm{C}$ and pressure range from 50 to $110 \mathrm{~atm}$ with constant mixing for $3 \mathrm{~h}$. After completion of the reaction, the autoclave was quickly cooled to room temperature and the pressure was released to atmospheric pressure. The analysis of the products was carried out by the simulated distillation method.

The SGK-5 catalyst is intended for the process of selective hydrocracking of n-paraffinic hydrocarbons in petroleum fractions and hydrodewaxing of oil fractions in order to obtain waxy transformer, hydraulic, mineral oils and other waxy products. The catalyst has enhanced hydrogenating properties and may be used for simultaneous hydrodewaxing and hydrotreating of secondary oil distillates. The catalyst represents granules consisting of a high-silica zeolite of pentasil group (structural analogue of ZSM-5) and hydrogenating components, the characteristics of the catalyst are shown in Table 1.

Table 1. Physical and chemical characteristics of the SGK-5 catalyst.

\begin{tabular}{cc}
\hline Indicator & Indicator Value \\
\hline Bulk density, $\mathrm{g} / \mathrm{cm}^{3}$ & $0.8-0.9$ \\
Diameter of granules, $\mathrm{mm}$ & $2.5-3.5$ \\
Chemical composition, $\boldsymbol{w}$ t\% \\
$\mathrm{MoO}_{3}$ & $10-12$ \\
$\mathrm{NiO}$ & $5-6$ \\
$\mathrm{Na}_{2} \mathrm{O}$ & 0,2 \\
\hline
\end{tabular}

Experimental studies of the effect of process severity on the composition and yield of oil sludge processing products using the commercial catalyst SGK-5 have been carried out. Catalyst loading was $200 \mathrm{mg}$, reaction time was $3 \mathrm{~h}$. The $\mathrm{H}_{2}$-to-feed stock ratio was 800,1100 , and $1700 \mathrm{ncm}^{3} / \mathrm{cm}^{3}$ (corresponding to the experiments at 50, 70, and $110 \mathrm{~atm}$ ).

\subsection{Methodology of Low-Temperature Hydrogenation in Sorbing Electrochemical Matrices}

For purification of oil sludge using the method of low-temperature hydrogenation in sorbing electrochemical matrices, a unit for vapor phase dispersion of oil sludge in polycomplexone solutions (Figure 1) and a sorbing electrochemical matrix were developed. To create it, we used parallel connected conductors, $15 \mathrm{~cm}$ long each. Conductor ends, $1.5 \mathrm{~cm}$ long each, were in anolyte (solution of $\mathrm{NaOH}$ $(3 \mathrm{~mol} / \mathrm{L})$ with carbon anode) and in catolyte $(\mathrm{NaOH}$ solution $(3 \mathrm{~mol} / \mathrm{L}))$. Containers were made of high density polyethylene (HDP). A clearance of $0.5 \mathrm{~cm}$ was between anolyte and the container. A contact connected with the "plus" terminal was attached to this section of the conductor.

Asbestos cloth chemically copulated by a layer of active carbon with grafted ethanolamine PVC derivatives and sodium hydroxide aquacomplexes was used as an electron- $\mathrm{OH}^{-}$-conducting hydrogen-producing conductor [19]. Layer mass content is 38.7\%, mass content of carbon in the layer is $76.2 \%$, the content of sodium hydroxide is $3.2 \mathrm{mmol} / \mathrm{g}$. Sorption capacity when absorbing benzene vapors is $11.9 \mathrm{mmol} / \mathrm{g}$ (layer). The photo of the conductor is given in Figure 2.

The content of water was determined by Karl Fischer titration (GOST R 54284-2010). The content of metal porphyrin complexes was identified by luminescence [26]. 


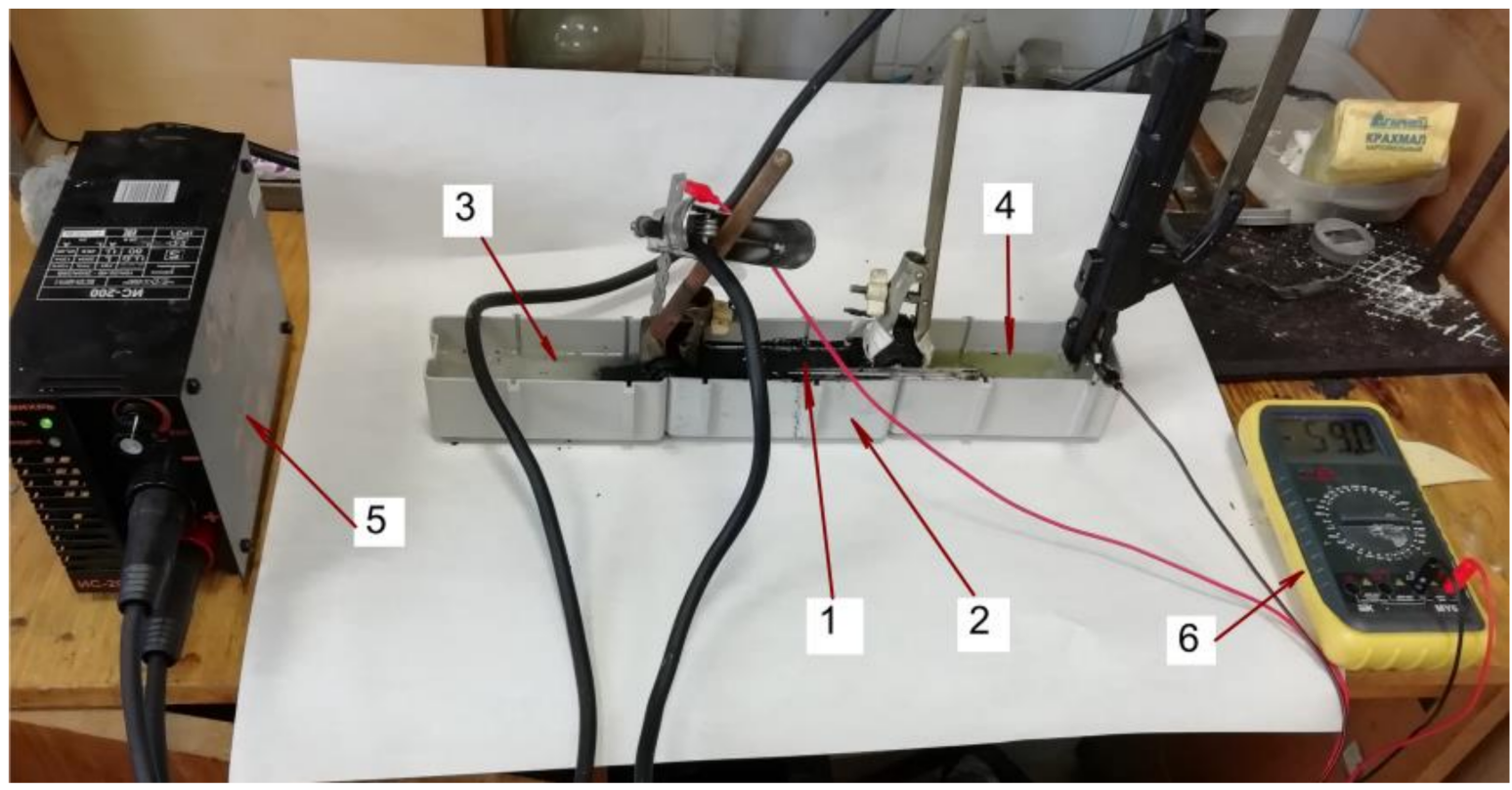

Figure 1. Sorbing electrochemical matrix (1-conductor, 2-reaction container, 3-catolyte (container with $\mathrm{NaOH}$ solution $(3 \mathrm{~mol} / \mathrm{L}))$, 4 -anolyte (container with the solution of $\mathrm{NaOH}(3 \mathrm{~mol} / \mathrm{L})$ with carbon anode), 5-direct current source, 6-multimeter).

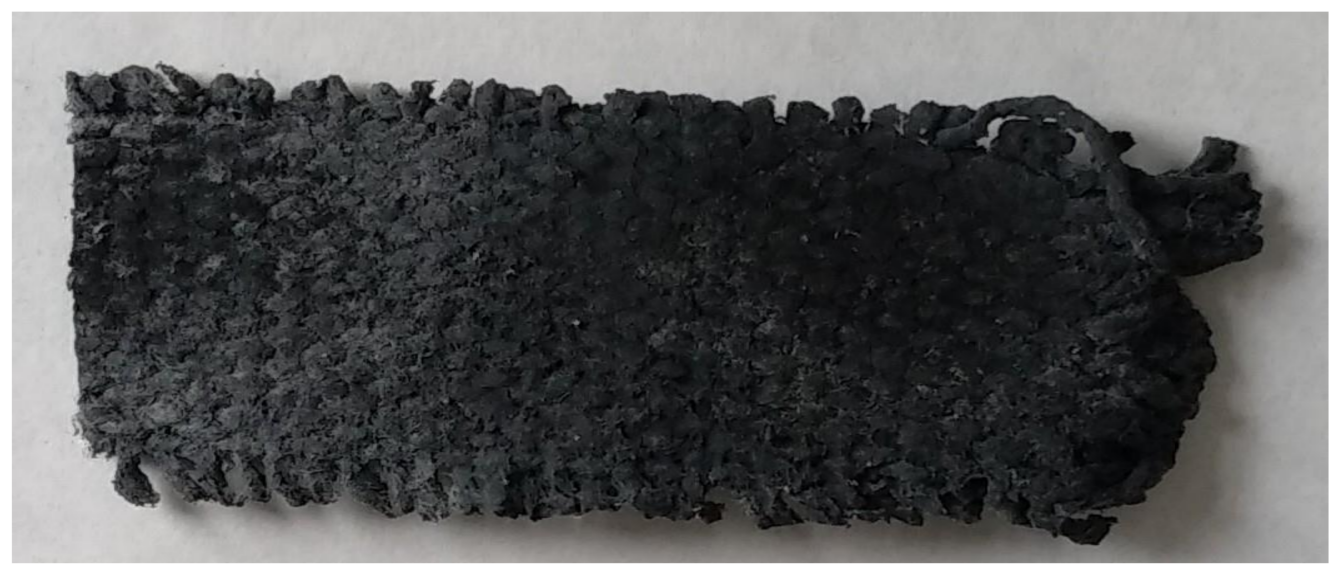

Figure 2. Conductor used in matrix.

\section{Results and Discussion}

\section{Processing of Oil Sludges by Hydrocracking}

The task of synthesizing the acidic component of carrier for the hydrocracking catalyst is rather difficult. This is due to the fact that the carrier must exhibit certain textural properties, in particular, a high specific surface area and an optimal acidity spectrum: to crack large molecules of heavy feedstock, the carrier must have a large number of acid sites active within a temperature range of 300 to $400{ }^{\circ} \mathrm{C}$.

It was expected that the use of structured micro/mesoporous aluminosilicates with different acidic characteristics, acting as active components of the carriers, would allow optimizing the hydrocracking catalyst composition and hydrogenating sulphur compounds most effectively. The choice of the above materials among other mesoporous aluminosilicates was based on the fact that these materials have a pore size more than $40 \AA$; their synthesis is conducted in mild conditions, and the acidic properties can be regulated at the stage of synthesis. For the purpose, four different types of micro/mesoporous aluminosilicates have been obtained, all having high specific surface areas and 
rather strong acidic properties. The physicochemical characteristics of the obtained materials are described in publications [20,27]. Based on the synthesized alumino-silicates, sulphide Ni-W catalysts have been obtained and their activity in the oil sludge hydrocracking process has been studied.

To compare the effectivity of the synthesized catalysts of oil sludge hydrocracking, a series of experiments has been carried out using the SGK-5 industrial catalyst.

The results of the catalytic experiments are shown in Table 2. The experiments have shown that in the studied temperature range, the main products of oil sludge hydrocracking were hydrocarbons of diesel fraction. The maximum yield of light products was observed in experiments at a process temperature of $400{ }^{\circ} \mathrm{C}$ and an initial hydrogen pressure of $110 \mathrm{~atm}\left(\mathrm{H}_{2}\right.$-to feed stock $\left.=1700 \mathrm{ncm}^{3} / \mathrm{cm}^{3}\right)$.

Table 2. Influence of the severity of process conditions on the yield of light fractions in oil sludge hydrocracking on the SGK-5 catalyst.

\begin{tabular}{ccccccc}
\hline & & \multicolumn{3}{c}{ Products } & Yield of Liquid \\
P, atm. & $\mathbf{T},{ }^{\circ} \mathbf{C}$ & $\begin{array}{c}\text { Yield of Gasoline } \\
\text { Fraction, } \mathbf{\%}\end{array}$ & $\begin{array}{c}\text { Yield of Diesel } \\
\text { Fraction, } \mathbf{\%}\end{array}$ & $\begin{array}{c}\text { Ultimate } \\
\text { Yield, } \%\end{array}$ & Gas Yield, \% \\
\hline $\mathbf{5 0}$ & 400 & 2 & 16 & 18 & 89 & 11 \\
$\mathbf{5 0}$ & 450 & 4 & 16 & 20 & 86 & 14 \\
$\mathbf{5 0}$ & 500 & 6 & 17 & 23 & 79 & 21 \\
$\mathbf{7 0}$ & 400 & 4 & 18 & 22 & 79 & 21 \\
$\mathbf{7 0}$ & 450 & 5 & 20 & 25 & 75 & 25 \\
$\mathbf{7 0}$ & 500 & 7 & 19 & 26 & 79 & 32 \\
$\mathbf{1 1 0}$ & 400 & 4 & 29 & 33 & 68 & 25 \\
$\mathbf{1 1 0}$ & 450 & 7 & 21 & 28 & 75 & 25 \\
$\mathbf{1 1 0}$ & 500 & 8 & 22 & 30 & 75 & \\
\hline
\end{tabular}

The results obtained show dependence of the yield of liquid products on the process temperature. At an initial hydrogen pressure of $50 \mathrm{~atm}$ observed is the determinate decrease in the yields of liquid reaction products with the simultaneous increase in the gas yield and an in-crease in the process temperature. An increase in pressure is also accompanied by a decrease in the yield of liquid products and an increase in gas formation.

The sulphide Ni-W catalysts obtained on the basis of micro/mesoporous materials were tested during the oil sludge hydrocracking. The results are given in Table 3. For comparison, we present the results of the experiment conducted under the same conditions with the use of the SGK-5 industrial catalyst.

Table 3. Results of oil sludge hydrocracking experiments with the use of micro/mesoporous catalysts.

\begin{tabular}{|c|c|c|c|c|c|c|}
\hline Catalyst & \multicolumn{6}{|c|}{ Products } \\
\hline $\begin{array}{l}\text { NiS-WS }_{2} / \\
\text { SBA-15-MFI }\end{array}$ & 18 & 33 & 0.15 & $25 \%$ & 30 & 40 \\
\hline $\begin{array}{c}\text { NiS-WS }{ }_{2} / \\
\text { TUD-zeolite-BEA }\end{array}$ & 8 & 27 & 0.19 & $21 \%$ & 40 & 20 \\
\hline $\begin{array}{c}\text { NiS-WS } 2 / \\
\text { SBA-15-ZSM-5 }\end{array}$ & 5 & 25 & 0.20 & $25 \%$ & 42 & 16 \\
\hline $\begin{array}{c}\text { NiS-WS } \\
\text { SBA-15-zeolite-BEA }\end{array}$ & 3 & 18 & 0.25 & $17 \%$ & 46 & 12 \\
\hline
\end{tabular}

Catalysts NiS-WS 2 /SBA-15-MFI and NiS-WS 2 /MCM-41-ZSM-5 displayed maximum activity during oil sludge hydrocracking process because the yield of light fractions reached the largest values. 
For example, on the SBA-15-MFI-based catalyst, the ultimate yield of gasoline and diesel fractions was $51 \%$, the conversion of heavy fraction distillated at a boiling point of more than $500{ }^{\circ} \mathrm{C}$ was $40 \%$. On the NiS-WS $2 / \mathrm{MCM}-41-\mathrm{ZSM}-5$ catalyst, the ultimate yield was $48 \%$ and the conversion of heavy fraction- $38 \%$. Whereas in contrast, on the SGK-5 catalyst, the same indicators were $17 \%$ for the light fraction, and $10 \%$ for the conversion. Moreover, in the case of synthesized catalysts, the maximum yield of gas products was observed, which is an evidence of the presence of strong acidic sites. Thus, the yields increase in the series of carriers SBA-15-MFI > MCM-41-ZSM-5 > TUD-zeolite-BEA > SBA-15-ZSM-5 > SBA 15-zeolite-BEA, which correlates to the data on acidity and textural characteristics that decrease in this series.

The products of oil sludge hydrocracking on micro/mesoporous catalysts were defined by the simulated distillation method; the curves of true boiling points were plotted based on the data obtained (Figure 3). This graphic representation more clearly demonstrates the hydrocarbon fractions contained in hydrocracking products. So, for example, the products of oil sludge hydrocracking over catalyst NiS-WS 2 /MCM-41 ZSM- 5 contain more light hydrocarbons (T boil $<150{ }^{\circ} \mathrm{C}$ ) than the products obtained with the use of the catalyst NiS-WS $2 / \mathrm{SBA}-15 \mathrm{MFI}$, though the use of the latter catalyst resulted in the presence of more middle distillates in the hydrocracking products. Such results can be explained by the fact that the material of type MCM-41 ZSM-5, according to the data of the phase analysis by X-ray diffraction (PXRD) and $\mathrm{NH}_{3}$ temperature programmed desorption (TPD), has high crystallinity and acidity that allows obtaining lighter products. In its turn, the material of type SBA-15 MFI contains a less prominent crystalline phase but more structured mesopores, which is an important point for obtaining diesel fractions, because in this case diffusion limitations are almost completely removed and large molecules of feedstock quickly penetrate and exit from the pores of the catalyst, practically without cracking to gaseous products.

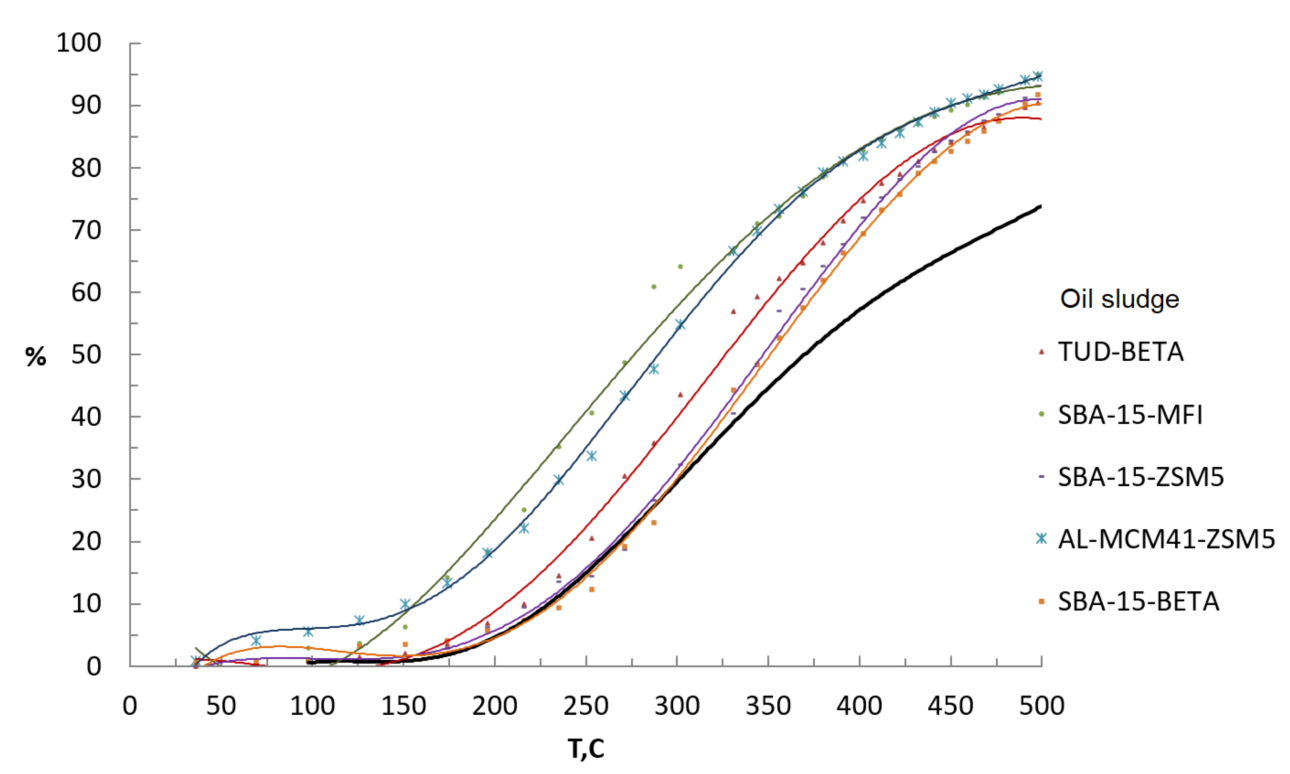

Figure 3. Curves of true boiling points of oil sludge hydrocracking products on micro/mesoporous catalysts (assuming that $p=90 \mathrm{~atm}, \mathrm{~T}=400{ }^{\circ} \mathrm{C}$, reaction time $-3 \mathrm{~h}, 500 \mathrm{mg}$ of catalyst).

Oil sludge processing using a sorbing electrochemical matrix.

As an alternative to the classical high-temperature oil sludge hydrocracking, we have proposed a method of low-temperature hydrogenation in sorbing electrochemical matrices.

For the purpose, we prepared three samples of water-oil emulsions with the following sludge/polycompexone ratios-4:1 (I) 3:2 (II) and 4.5:5.5 (III). Hydrogenation of water-oil emulsions was carried out in a sorbing electrochemical matrix (Figure 1). Emulsions were placed in a reaction container. The study was performed with specified current $\mathrm{J}=100 \mathrm{~A}$, hydrogen production rate was 
$0.051 \mathrm{mmol} / \mathrm{sec}$. During the process, we measured circuit voltage; using UV irradiation, monitored the appearance of $\mathrm{S}^{2-}$ or $\mathrm{SO}_{3}{ }^{2-}$ in emulsion and in anolyte, and also derivatives of polymucosaccharides and triglycerides. It was found that voltage increased from

$38-37 \mathrm{~V}$ to $42-34 \mathrm{~V}$ during 25-27 min, after which it achieved plateau. The appearance of $\mathrm{S}^{2-}$ in emulsion and $\mathrm{SO}_{3}{ }^{2-}$ in anolyte is indicative of the transformation of sulphur-containing compounds, at which sulphur is released, of $\mathrm{S}^{2-}$ transfer from the reaction mass to anolyte and their oxidation at the anode to $\mathrm{SO}_{3}{ }^{2-}$. The appearance of green luminescence in catolyte testifies to the presence of water-soluble porphyrin complexes of vanadium and zink, while the appearance of violet luminescence in anolyte-to the presence of porphyrin complexes of iron [15]. The simultaneous transition to catolyte and anolyte of polymucosaccharide derivatives during hydrogenation means the occurrence of the destruction of oil components with metal-porphyrin groups and the generation of polynuclear mixed-ligand metal complexes with ligand groups that are derivatives of polymucosaccharides and porphyrins. Depending on the total charge, they are transferred to catolyte or anolyte. Throughout the process, the yellowish-green luminescence of the emulsion disappears and a shade of blue appears. Oil luminescence depends on its group composition and the specified change in luminescence corresponds to a decrease in the content of resins and heavy aromatic compounds. Similar processes take place during high-temperature hydrogenation of oil.

Separation of emulsions into oil and water phases was performed with the use of nitrilotriacetic acid. It was found that during emulsion separation, derivatives of triglycerides of fatty acids passed into the oil phase while polymucosaccharide derivatives-into the water phase. Table 4 presents the data on the content of sulphur and metals in oil phases.

Table 4. Contents of sulphur and metals in oil phase after low-temperature hydrogenation in sorbing electrochemical matrices.

\begin{tabular}{ccccc}
\hline \multirow{2}{*}{ Element } & \multirow{2}{*}{ Oil Sludge } & \multicolumn{3}{c}{ Oil Phase Separated from Emulsion } \\
\cline { 3 - 5 } & & I & II & III \\
\hline $\mathbf{S , \%}$ & 4.67 & 0.032 & 0.0015 & N/A \\
$\mathbf{W}, \%$ & 0.029 & 0.0022 & 0.0004 & 0.0001 \\
$\mathbf{N i} \%$ & 0.0079 & 0.0006 & 0.00023 & 0.00016 \\
$\mathbf{Z n}, \%$ & 0.094 & 0.014 & 0.0004 & 0.0002 \\
$\mathbf{C u} \%$ & 0.0022 & 0.006 & - & - \\
$\mathbf{F e} \%$ & 0.102 & 0.003 & 0.0007 & 0.0004 \\
\hline
\end{tabular}

We can observe from the table that the content of sulphur and metals decreases when the share of polycomplexones in emulsion increases. It is worth noting that the sulphur content in the oil phase after low-temperature hydrogenation in sorbing electrochemical matrices is by an order of magnitude less than after high-temperature hydrocracking.

After the hydrogenation of water-oil emulsions is completed, the oil phase was dehydrated by water stripping at 85 to $90^{\circ} \mathrm{C}$. The density and viscosity of obtained synthetic crude oils are given in the table (Table 5).

Table 5. Physical and chemical properties of synthetic crude oils.

\begin{tabular}{ccccc}
\hline \multirow{2}{*}{ Element } & \multirow{2}{*}{ Oil Sludge } & \multicolumn{3}{c}{ Oil Phase Separated from Emulsion } \\
\cline { 3 - 5 } & & I & II & III \\
\hline Density, $\mathbf{g} / \mathbf{c m}^{\mathbf{3}}$ & 0.998 & 0.856 & 0.871 & 0.874 \\
Viscosity, $\mathbf{P a} \mathbf{s}$ & 7.08 & 2.17 & 2.05 & 1.96 \\
\hline
\end{tabular}

The group composition was established for oil obtained from oil phase III (Table 6). 
Table 6. Group composition of oil from oil phase III separated from emulsion.

\begin{tabular}{ccc}
\hline Indicator & Oil Sludge & Synthetic Crude Oil \\
\hline Paraffins and naphthenes & 38.2 & 58.9 \\
Light aromatic hydrocarbons & 17.3 & 10.5 \\
Medium aromatic hydrocarbons & 5.6 & 2.8 \\
Heavy aromatic hydrocarbons & 11.8 & 8.7 \\
Resins & 7.8 & 7.1 \\
Oxidized resins & 8 & 4.01 \\
Asphaltenes & 8.8 & 5.3 \\
\hline
\end{tabular}

Before hydrogenation, the water-oil emulsion contained about $40 \mathrm{~g}$ of iminodiacetate derivatives of triglycerides per $100 \mathrm{~g}$ of sludge. In the group composition, they are determined together with paraffins and naphthenes. If the amount of other components remained unchanged, then the content of paraffins and naphthenes should have increased to $55.8 \%$, while the content of other components should have decreased by 1.4 times. In fact, the share of paraffins and naphthenes increased to $58.9 \%$, i.e., by $3.1 \%$ above the expected one. The share of light aromatic hydrocarbons decreased by $1.85 \%$, and of medium aromatic hydrocarbons-by $1.2 \%$ as compared with the expected one. The content of oxidized resins and asphaltenes decreased by $1.7 \%$ and $1 \%$, and of heavy aromatic hydrocarbons and resins increased by $0.3 \%$ and $1.5 \%$, as compared with the expected content. Metal complexes and sulphur-containing compounds are concentrated in resins and asphaltenes. During hydrogenation, a partial destruction of resins and asphaltenes occurs, owing to which the transformation of sulphur-containing compounds and the release of metal porphyrins become possible.

\section{Conclusions}

The results obtained are illustrative of the processing of reservoir oil sludges into synthetic crude oil by the method of low-temperature hydrogenation in sorbing electrochemical matrices and also the prospects of this method as compared to classical hydrocracking.

These two methods of oil sludge processing enormously vary in their essence and products obtained at the end of processes. In the process of low-temperature hydrogenation, synthetic crude oil is obtained in sorbing electrochemical matrices, which can be further used to obtain valuable petroleum feedstock. In turn, during hydrocracking, we obtain fuel fractions that, after subsequent stages of treatment, can be used as fuel. However, in order to obtain light fractions, hydrocracking must be followed by further refinement, including desulphuration. At this stage, it is already clear that each of the methods considered above has its advantages and disadvantages and thereafter they can complement each other.

During low-temperature hydrogenation in sorbing electrochemical matrices, polymucosaccharide and triglyceride derivatives are polyampholytes through which resins and asphaltenes diffuse $\mathrm{H}_{2}$ and $\mathrm{OH}^{-}$obtained as a result of chemical reaction $2 \mathrm{H}_{2} \mathrm{O}+2 \mathrm{e}=\mathrm{H}_{2}+\mathrm{OH}^{-}$. They interact with suphur-containing groups to form hydrocarbon groups and $\mathrm{S}^{2-}, \mathrm{H}_{2} \mathrm{O}$. Released $\mathrm{S}^{2-}$ are transferred to the solution with the anode where they are oxidized with the participation of $\mathrm{OH}^{-}$to $\mathrm{SO}_{3}{ }^{2-}$. Iminodiacetate groups of polymucosaccharide derivatives and triglyceride derivatives coordinate the ions of metals bound to porphyrin radicals in sorbed agglomerates on conductor layers. Since complexes containing porphyrin ligands are transferred to catolyte and anolyte, it can be assumed that iminodiacetate groups with the help of $\mathrm{H}_{2}$ and $\mathrm{OH}^{-}$promote the rupture of bonds between groups in asphaltenes, resins and porphyrin groups. Polymucosaccharide derivatives are polyanions that are transferred via the conductor to anolyte. In case of $\mathrm{VO}^{-}, \mathrm{Ni}^{2+}, \mathrm{Zn}^{2+}$ and $\mathrm{Cu}^{2+}$, spheres of polynuclear complex may not have a charge. Porphyrins of these metals bound to macromolecular polyanion are transferred to anolyte. $\mathrm{Fe}^{3+}$ spheres have a positive charge and polynuclear complexes with such spheres are transferred to catolyte. The conductor is capable of sorbing aromatic hydrocarbons. It appears that if and when destruction of agglomerates on carbon particles occurs, aromatic hydrocarbons, including 
resins and asphaltenes, are hydrogenated. Hydrogenation of light and medium aromatic hydrocarbons results in an increase in the share of paraffins and naphthenes while hydrogenation of heavy aromatic hydrocarbons-in an increase in the share of asphaltenes and resins.

The oil obtained by hydrogenation in sorbing electrochemical matrices can be classified as medium density low-viscosity oil, with no sulphur, with a low content of metals, enriched by components of "biodiesel", since triglyceride derivatives can be considered as analogs of fatty acid esters. Taking into account that the detergent used in this study is a product produced from renewable protein containing wastes and that it is effective in processing bulk hazardous wastes, we can say that interest in further study of this process will only grow.

Author Contributions: Conceptualization A.M. and A.T.; methodology A.N.; investigation, A.F. and M.S.; writing—original draft preparation A.F.; writing—review and editing, T.K., E.N. All authors have read and agreed to the published version of the manuscript.

Funding: The study was carried out with financial support from the Russian Foundation for Basic Research with-in the framework of scientific project No. 18-29-24137 (study of oil sludge treatment using a sorbing electrochemical matrix). The work has been carried out in frames of the State Program of TIPS RAS (study of oil sludge hydrocracking).

Conflicts of Interest: The authors declare no conflict of interest.

\section{References}

1. Olajire, A.A.; Altenburger, R.; Kuster, E.; Brack, W. Chemical and ecotoxicological assessment of polycyclic aromatic hydrocarbon-Contaminated sediments of the Niger Delta, Southern Nigeria. Sci. Tot. Environ. 2005, 340, 123-136. [CrossRef] [PubMed]

2. Pereira Netto, A.D.; Moreira, J.C.; Dias, A.E.X.; Arbilla, G.; Ferreira, L.F.V.; Oliveira, A.S.; Barek, J. Assessment of human contamination by polycyclic aromatic hydrocarbons (HPAs) and their nitrate derivatives (NPAH): A methodological revision. Quim. Nova 2000, 23, 765-773. [CrossRef]

3. Song, Q.; Zhao, H.; Jia, J.; Zhang, F.; Wang, Z.; Lv, W.; Yang, L.; Zhang, W.; Zhang, Y.; Shu, X. Characterization of the products obtained by pyrolysis of oil sludge with steel slag in a continuous pyrolysis-magnetic separation reactor. Fuel 2019, 255, 115711. [CrossRef]

4. Chen, G.; Cheng, C.; Zhang, J.; Sun, Y.; Hu, Q.; Qu, C.; Dong, S. Synergistic effect of surfactant and alkali on the treatment of oil sludge. J. Pet. Sci. Eng. 2019, 183, 106420. [CrossRef]

5. Cheng, S.; Takahashi, F.; Gao, N.; Yoshikawa, K.; Li, A. Evaluation of Oil Sludge Ash as a Solid Heat Carrier in the Pyrolysis Process of Oil Sludge for Oil Production. Energy Fuel 2016, 30, 5970-5979. [CrossRef]

6. Anisimov, A.V.; Frolov, V.I.; Ivanov, E.V.; Karakhanov, E.A.; Lesin, S.V.; Vinokurov, V.A. Complex Technology of Oil Sludge Processing. In Proceedings of the Scientific-Practical, Conference "Research and Development-2016"; Anisimov, K., Ed.; Springer: Cham, Switzerland, 2018; pp. 617-623. [CrossRef]

7. Raya, S.A.; Mohd, S.I.; Abbas, A.A.; Abubakar, U.A. A critical review of development and demulsification mechanisms of crude oil emulsion in the petroleum industry. J. Pet. Explor. Prod. Technol. 2020, 10, 1711-1728. [CrossRef]

8. Fingas, M.; Fieldhouse, B. Studies of the formation process of water-in-oil emulsions. Mar. Pollut. Bull. 2003, 47, 369-396. [CrossRef]

9. Duan, M.; Yao, M.; Zhao, B.; Chen, B.; Xiong, Y.; Fang, S.; Zhao, Y. The dissolution of oil sludge formed by flocculation of oily wastewater produced from polymer flooding. Can. J. Chem. Eng. 2019, 97, 1283-1288. [CrossRef]

10. Ramirez, D.; Collins, C.D. Maximisation of oil recovery from an oil-water separator sludge: Influence of type, concentration, and application ratio of surfactants. Waste Manag. 2018, 82, 100-110. [CrossRef]

11. Tsivadze, A.Y.; Fridman, A.Y.; Maksimov, A.L.; Polyakova, I.Y.; Gorbunov, A.M.; Petrukhina, N.N.; Shabanov, M.P. A Detergent Prepared from Iminodiacetate Derivatives of Fats and Polymucosaccharides from Base Hydrolyzates of Protein-Containing Waste. Russ. J. Appl. Chem. 2020, 93, 333-339. [CrossRef]

12. Kundu, P.; Mishra, I.M. Treatment and reclamation of hydrocarbon-bearing oily wastewater as a hazardous pollutant by different processes and technologies: A state-of-the-art revie. Rev. Chem. Eng. 2018, 35. [CrossRef]

13. Tsivadze, A.Y.; Fridman, A.Y.; Tumanyan, B.P.; Maksimov, A.L.; Novikov, A.K.; Polyakova, I.Y.; Gorbunov, A.M.; Petrukhina, N.N.; Shabanov, M.P. Peculiarities of Dispersion of Oil Raw Materials into Aqueous Solutions of Polycomplexones Surfactants. Chem. Technol. Fuels Oils 2020, 56, 124-128. [CrossRef] 
14. Kreuer, K.D. Ion Conducting Membranes for Fuel Cells and other Electrochemical Devices. Chem. Mater. 2013, 26, 361-380. [CrossRef]

15. Liu, Y.L. Developments of highly proton-conductive sulfonated polymers for proton exchange membrane fuel cells. Polym. Chem. 2012, 3, 1373. [CrossRef]

16. Vetter, S.; Ruffmann, B.; Buder, I.; Nunes, S.P. Proton conductive membranes of sulfonated poly(ether ketone ketone). J. Membr. Sci. 2005, 260, 181-186. [CrossRef]

17. Mastragostino, M. Conducting polymers as electrode materials in supercapacitors. Solid State Ion. 2002, 148, 493-498. [CrossRef]

18. Brown, N.; Roberts, E.P.L.; Chasiotis, A.; Cherdron, T.; Sanghrajka, N. Atrazine removal using adsorption and electrochemical regeneration. Water Res. 2004, 38, 3067. [CrossRef]

19. Tsivadze, A.Y.; Fridman, A.Y.; Voloshchuk, A.M.; Morozova, E.M.; Sokolova, N.P.; Bardyshev, I.I.; Gorbunov, A.M.; Novikov, A.K.; Petukhova, G.A.; Polyakova, I.Y.; et al. Electrochemically reactive matrices based on electron-ion conducting and adsorption-active tissues. Russ. J. Electrochem. 2016, 53, 39-48. [CrossRef]

20. Naranov, E.R.; Sadovnikov, A.A.; Maximov, A.L.; Karakhanov, E.A. Development of micro-mesoporous materials with lamellar structure as the support of NiW catalysts. Microporous Mesoporous Mater. 2018, 263, 150-157. [CrossRef]

21. Vu, X.H.; Steinfeldt, N.; Armbruster, U.; Martin, A. Improved hydrothermal stability and acidic properties of ordered mesoporous SBA-15 analogs assembled from nanosized ZSM-5 precursors. Microporous Mesoporous Mater. 2012, 164, 120-126. [CrossRef]

22. Do, T.-O.; Nossov, A.; Springuel-Huet, M.-A.; Schneider, C.; Bretherton, J.L.; Fyfe, C.; Kaliaguine, S. Zeolite Nanoclusters Coated onto the Mesopore Walls of SBA-15. J. Am. Chem. Soc. 2004, 126, 14324. [CrossRef] [PubMed]

23. Rutkowska, M.; Chmielarz, L.; Macina, D.; Piwowarska, Z.; Dudek, B.; Adamski, A.; Witkowski, S.; Sojka, Z.; Obalová, L.; Van Oers, C.; et al. Catalytic decomposition and reduction of $\mathrm{N}_{2} \mathrm{O}$ over micro-mesoporous materials containing Beta zeolite nanoparticles. Appl. Catal. B 2014, 146, 112-122. [CrossRef]

24. Lima, S.; Antunes, M.M.; Fernandes, A.; Pillinger, M.; Ribeiro, M.F.; Valente, A.A. Catalytic cyclodehydration of xylose to furfural in the presence of zeolite H-Beta and a micro/mesoporous Beta/TUD-1 composite material. Appl. Catal. A Gen. 2010, 388, 141-148. [CrossRef]

25. Li, Y.; Pan, D.; Yu, C.; Fan, Y.; Bao, X. Synthesis and hydrodesulfurization properties of NiW catalyst supported on high-aluminum-content, highly ordered, and hydrothermally stable Al-SBA-15. J. Catal. 2012, 286, 124-136. [CrossRef]

26. Valicsek, Z.; Horváth, O. Application of the electronic spectra of porphyrins for analytical purposes: The effects of metal ions and structural distortions. Microchem. J. 2013, 107, 47-62. [CrossRef]

27. Naranov, E.R.; Badeeva, A.S.; Sadovnikov, A.A.; Kardashev, S.V.; Maksimov, A.L.; Lysenko, S.V.; Vinokurov, V.A.; Karakhanov, E.A. Hydrogenation of aromatic hydrocarbons over nickel-tungsten sulfide catalysts containing mesoporous aluminosilicates of different nature. Pet. Chem. 2016, 56, 599-606. [CrossRef]

Publisher's Note: MDPI stays neutral with regard to jurisdictional claims in published maps and institutional affiliations.

(C) 2020 by the authors. Licensee MDPI, Basel, Switzerland. This article is an open access article distributed under the terms and conditions of the Creative Commons Attribution (CC BY) license (http://creativecommons.org/licenses/by/4.0/). 